\title{
A Study of Psychiatric Co-Morbidity in Patients Suffering from Thyroid Dysfunction
}

\author{
Authors \\ Kusum Bali ${ }^{1}$, Deepali Gul ${ }^{2}$
}

Department of Psychiatry, Punjab Institue of Medical Sciences, Garha Road, Jalandhar, Punjab (INDIA)

Corresponding Author

Deepali Gul

\begin{abstract}
Introduction: The association between thyroid function and mental health has been long recognized. Both excess and insufficient thyroid hormones can cause significant anxiety and depression. AIM: We aimed at finding out the nature and extent of psychiatric co-morbidity in patients suffering from thyroid dysfunction in a teaching hospital located in Jalandhar (Punjab).

Material and Methods: A cross-sectional study was carried out and fifty consecutive patients diagnosed as having thyroid dysfunction after taking an informed consent, were included in the study. The patients were assessed with a self-structured questionnaire for recording the socio-demographic variables, Hamilton Rating Scale for depression, Amritsar Depressive Inventory and the Hamilton Rating Scale for Anxiety. The patients were assessed by a psychiatrist and assigned a diagnosis as per the I.C.D.-10 criteria, where applicable.

Observations and Results: The sample consisted of 50 patients out of which 12(24\%) were males and $38(76 \%)$ were females. The mean age of the sample was 38.7 years. 34(68\%) patients were diagnosed as having hypothyroidism out of which 32(94.1\%) were females. $16(32 \%)$ patients were diagnosed as having hyperthyroidism out of which 10(62.5\%) were males. 9(56.3\%) of the hypothyroid patients scored 18 or more on Hamilton Rating Scale for Anxiety, indicative of moderate to severe anxiety. Of the 34 patients suffering from Hypothyroidism, 16(47.1\%) were found to have moderate to severe anxiety. Of the 34 patients diagnosed as having hypothyroidism, 16 (47.1\%) patients were found to have significant depression. The corresponding figure for hyperthyroidism was 5(31.3\%). 15 of the 34(44.1\%) patients of hypothyroidism had an Axis - I Diagnosis of Depressive episode as per the I.C.D.-10 criteria. Of the 16 hyperthyroid patients 5 (31.3\%) were diagnosed to have Panic Disorder.

Clinical Implications: The findings of our study underscore the need of a liaison with a psychiatrist in every patient of thyroid dysfunction. This would greatly help improve the quality of life of these patients and would lead to better outcomes both in the short and longterm..

Keywords: Depression, Anxiety, Hypothyroidism, Hyperthyroidism.
\end{abstract}

\section{Introduction}

The association between thyroid function and mental health has been long recognized. From a historical perspective, this association was first described more than 200 years ago. Parry in 1825 reported an increased incidence of "nervous 
affectations" in thyroid disorders. Gull in 1873 showed the relation between myxedema and psychosis. Later, Asher in 1949 coined the term "myxedema madness" to describe the mental state of patients suffering from hypothyroidism. ${ }^{(1)}$ Today, it is well recognized that disturbances in thyroid function may have a significant effect on mental health encompassing emotion and cognition. Both excess and insufficient thyroid hormones can cause significant anxiety and depression. $^{(2)}$

The present study aimed at finding out the nature and extent of psychiatric co-morbidity in patients suffering from thyroid dysfunction in a teaching hospital located in Jalandhar (Punjab).

\section{Material and Methods}

A cross-sectional study was carried out at the Outpatient facility of the Department of Medicine and Psychiatry of Punjab Institute of Medical Sciences, Jalandhar (PUNJAB). Fifty consecutive patients coming to the Out-patient facility of Department of Medicine diagnosed as having thyroid dysfunction after taking an informed consent, were included in the study.

The patients were assessed using the following tools:

1. Sociodemographic information of the patients was obtained using a semistructured proforma specially designed for the study.

2. Hamilton Depression Rating Scale for assessment of depression ${ }^{(3)}$

The HDRS is the most widely used multiple-item questionnaires to assess the severity of, and change in, depressive symptoms. It is considered the "gold standard" for rating depression in clinical research. It contains 17 items (HDRS-17) pertaining to symptoms of depression experienced over the past week. It is a clinician-administered depression assessment scale and the time required for its administration is $20-30 \mathrm{~min}$. The questionnaire is designed for adults and is used to rate the severity of their depression by probing mood, feelings of guilt, suicide ideation, insomnia, agitation or retardation, anxiety, weight loss, and somatic symptoms. Each item on the questionnaire is scored on a 3- or 5-point scale depending on the item.

3. Hamilton Anxiety Rating Scale (H.A.R.S.) for assessment of anxiety ${ }^{(4)}$

The H.A.R.S. was one of the first rating scales developed with a main purpose to assess the severity of symptoms of anxiety in adults, adolescents, and children. The scale consists of 14 items, each defined by a series of symptoms, and measures both psychic anxiety (mental agitation and psychological distress) and somatic anxiety (physical complaints related to anxiety). It is a clinician-rated scale; time required for administration is $10-15 \mathrm{~min}$. The scale consists of 14 items designed to assess the severity of a patient's anxiety. Each of the 14 items contains a number of symptoms, and each group of symptoms is rated on a scale of $0-4$, with four being the most severe. All of these scores are used to compute an overarching score that indicates a person's anxiety severity.

Both the tools were used in English language

4. Amritsar Depressive Inventory (A.D.I.) ${ }^{(5)}$ which is a patient-rated scale to screen for depressive symptoms.

Subsequently, all the patients included in the study were interviewed and assessed by a psychiatrist and diagnosed as per the I.C.D.-10 criteria.

The results so obtained were analyzed with the help of statistical methods like percentages and averages. T-tests were used wherever comparison between two patient groups was deemed necessary.

\section{Observations and Results}

The study sample consisted of 50 patients out of which $12(24 \%)$ were males and $38(76 \%)$ were females. The mean age of the sample was 38.7 years. The mean age of the male patients was 41.2 years while that of female patients was 38.2 years. 


\section{JMSCR Vol||05||Issue||12||Page 31711-31716||December}

$41(82 \%)$ of the patients were married. $10(83.4 \%)$ of the male patients were either self-employed or employed with the government while among the female patients $28(73.7 \%)$ were home-makers and only $9(23.7 \%)$ were employed. $15(30 \%)$ of the patients were educated upto matric while another $12(24 \%)$ were graduates. 24(48\%) patients each practiced Hindu and Sikh religion. 30(60\%) of the patients resided in urban areas while 20(40\%) resided in rural areas (Table -1$)$.

Table. No 1 socio-demographic variables

\begin{tabular}{|c|c|c|c|}
\hline & $\begin{array}{c}\text { Male } \\
\text { patients }\end{array}$ & $\begin{array}{l}\text { Female } \\
\text { patients }\end{array}$ & Overall \\
\hline Mean Age (years) & 40.17 & 38.24 & 38.70 \\
\hline $\begin{array}{l}\text { MARITAL } \\
\text { STATUS }\end{array}$ & $\begin{array}{c}\text { Number } \\
\text { of Male } \\
\text { patients } \\
(\mathrm{N}=12) \\
(\%)\end{array}$ & $\begin{array}{c}\text { Number } \\
\text { of female } \\
\text { patients } \\
(\mathrm{N}=38) \\
(\%)\end{array}$ & $\begin{array}{c}\text { Total } \\
\text { number } \\
\text { of } \\
\text { patients } \\
(\mathbf{N}=50) \\
(\%)\end{array}$ \\
\hline Married & $8(66.7)$ & $33(86.8)$ & $41(82.0)$ \\
\hline Unmarried & $4(33.3)$ & $5(13.2)$ & $9(18.0)$ \\
\hline \multicolumn{4}{|l|}{ OCCUPATION } \\
\hline Self-employed & $5(41.7)$ & $4(10.5)$ & $9(18.0)$ \\
\hline Govt employee & $5(41.7)$ & $5(13.2)$ & $10(20.0)$ \\
\hline Student & $2(16.7)$ & $1(2.6)$ & $3(6.0)$ \\
\hline House wife & 0 & $28(73.7)$ & $28(56.0)$ \\
\hline \multicolumn{4}{|l|}{$\begin{array}{l}\text { EDUCATIONAL } \\
\text { ATTAINMENT }\end{array}$} \\
\hline Illiterate & 0 & $3(7.9)$ & $3(6.0)$ \\
\hline Primary & $1(8.3)$ & 0 & $1(2.0)$ \\
\hline Middle & 0 & $2(5.3)$ & $2(4.0)$ \\
\hline Matric & $1(8.3)$ & $14(36.8)$ & $15(30.0)$ \\
\hline $10+2$ & $3(25.0)$ & $7(18.4)$ & $10(20.0)$ \\
\hline Graduate & $4(33.3)$ & $8(21.1)$ & $12(24.0)$ \\
\hline Post-graduate & $3(25.0)$ & $4(10.5)$ & $7(14.0)$ \\
\hline \multicolumn{4}{|l|}{ RELIGION } \\
\hline Hindu & $4(33.3)$ & $20(52.6)$ & $24(48.0)$ \\
\hline Sikh & $8(66.6)$ & $16(42.1)$ & $24(48.0)$ \\
\hline Muslim & 0 & $2(5.3)$ & $2(4.0)$ \\
\hline \multicolumn{4}{|l|}{$\begin{array}{ll}\text { PLACE } & \text { OF } \\
\text { RESIDENCE } & \end{array}$} \\
\hline Rural & $6(50.0)$ & $14(36.8)$ & $20(40.0)$ \\
\hline Urban & $6(50.0)$ & $24(63.2)$ & $30(60.0)$ \\
\hline
\end{tabular}

$34(68 \%)$ patients were diagnosed as having hypothyroidism out of which $32(94.1 \%)$ were females. $16(32 \%)$ patients were diagnosed as having hyperthyroidism out of which $10(62.5 \%)$ were males.

Of the 16 patients suffering from Hyperthyroidism, 9(56.3\%) scored 18 or more on Hamilton Rating Scale for Anxiety, indicative of moderate to severe anxiety (Table -3$)$. Of the total sample of 50 patients, $25(50 \%)$ scored 18 or more on the H.A.R.S. indicative of moderate to severe anxiety (Table - 3).

Table No 2 Scores on the H.D.R.S.

\begin{tabular}{|l|c|c|c|}
\hline $\begin{array}{l}\text { Scores on } \\
\text { H.D.R.S. }\end{array}$ & $\begin{array}{c}\text { Number of } \\
\text { Hypothyroid } \\
\text { patients } \\
(\mathrm{N}=34)(\%)\end{array}$ & $\begin{array}{c}\text { Number of } \\
\text { Hyperthyroid } \\
\text { patients } \\
(\mathrm{N}=16)(\%)\end{array}$ & $\begin{array}{c}\text { Total } \\
\text { number of } \\
\text { patients } \\
(\mathrm{N}=50) \\
(\%)\end{array}$ \\
\hline $0-6$ & $13(38.2)$ & $6(37.5)$ & $19(38.0)$ \\
\hline $7-17$ & $11(32.3)$ & $9(56.2)$ & $20(40.0)$ \\
\hline $18-24$ & $10(29.4)$ & $1(6.3)$ & $11(22.0)$ \\
\hline$>24$ & 0 & 0 & 0 \\
\hline
\end{tabular}

Of the 34 patients diagnosed as having hypothyroidism, $16(47.1 \%)$ patients were found to have significant depression. Of the 16 patients diagnosed as having hyperthyroidism 5 (31.3\%) patients had significant depression (Table -2$)$.

Table No 3 Scores on the H.A.R.S

\begin{tabular}{|l|c|c|c|}
\hline $\begin{array}{l}\text { Scores on } \\
\text { H.A.R.S. }\end{array}$ & $\begin{array}{c}\text { Number of } \\
\text { Hypothyroid } \\
\text { patients } \\
(\mathrm{N}=34)(\%)\end{array}$ & $\begin{array}{c}\text { Number of } \\
\text { Hyperthyroid } \\
\text { patients } \\
(\mathrm{N}=16)(\%)\end{array}$ & $\begin{array}{c}\text { Total } \\
\text { Number of } \\
\text { patients } \\
(\mathrm{N}=50) \\
(\%)\end{array}$ \\
\hline$<14$ & $14(41.2)$ & $5(31.3)$ & $20(40.0)$ \\
\hline $14-17$ & $4(11.8)$ & $2(12.5)$ & $6(12.0)$ \\
\hline $18-24$ & $10(29.4)$ & $8(50.0)$ & $18(36.0)$ \\
\hline $25-30$ & $6(17.7)$ & $1(6.3)$ & $7(14.0)$ \\
\hline
\end{tabular}

16 of the $34(47.1 \%)$ patients having hypothyroidism scored 8 or more on the Amritsar Depressive Inventory (A.D.I.) indicative of significant depression while only 5 of $16(31.3 \%)$ patients diagnosed as having hyperthyroidism reported significant depression (Table -4$)$.

15 of the 34(44.1\%) patients of hypothyroidism had an Axis - I Diagnosis of Depressive episode as per the I.C.D.-10 criteria. Of the 16 hyperthyroid patients $5(31.3 \%)$ were diagnosed to have Panic Disorder (Table - 5). 
Table No 4 Scores on the A.D.I.

\begin{tabular}{|l|c|c|c|}
\hline $\begin{array}{l}\text { Scores } \\
\text { on A.D.I. }\end{array}$ & $\begin{array}{c}\text { Number of } \\
\text { Hypothyroid } \\
\text { patients } \\
(\mathrm{N}=34)(\%)\end{array}$ & $\begin{array}{c}\text { Number of } \\
\text { Hyperthyroid } \\
\text { patients } \\
(\mathrm{N}=16)(\%)\end{array}$ & $\begin{array}{c}\text { Total } \\
\text { number of } \\
\text { patients } \\
(\mathrm{N}=50)(\%)\end{array}$ \\
\hline$<8$ & $18(52.9)$ & $11(68.8)$ & $29(58.0)$ \\
\hline $8-13$ & $3(8.8)$ & $4(25.0)$ & $7(14.0)$ \\
\hline $14-20$ & $9(26.4)$ & 0 & $9(18.0)$ \\
\hline$>20$ & $4(11.8)$ & $1(6.3)$ & $5(10.0)$ \\
\hline
\end{tabular}

Table No 5 Table showing Axis-I Diagnosis

\begin{tabular}{|c|c|c|}
\hline Axis - I Diagnosis & $\begin{array}{c}\text { Hypothyroid } \\
\text { patients } \\
(\mathrm{N}=34)(\%)\end{array}$ & $\begin{array}{c}\text { Hyperthyroid } \\
\text { patients } \\
(\mathrm{N}=16)(\%)\end{array}$ \\
\hline Depressive episode & $15(44.1)$ & $2(12.5)$ \\
\hline Panic disorder & $1(2.9)$ & $5(31.3)$ \\
\hline $\begin{array}{c}\text { Generalized Anxiety } \\
\text { Disorder }\end{array}$ & 0 & $2(12.5)$ \\
\hline $\begin{array}{c}\text { Obsessive } \\
\text { Compulsive Disorder }\end{array}$ & 0 & $1(6.3$ \\
\hline
\end{tabular}

\section{Discussion}

Ours was a cross-sectional hospital-based study in which 50 consecutive patients suffering from Thyroid dysfunction reporting to the Outpatient Department of Medicine of P.I.M.S., Jalandhar (Punjab) and who gave a written consent for being included in the study, formed the study sample. The study sample consisted of 34(68\%) patients of Hypothyroidism and 16(32\%) patients of Hyperthyroidism. 32 of the $34(94.1 \%)$ hypothyroid patients were females while 10 of $16(62.5 \%)$ hyperthyroid patients were males. Previous researches have shown that in areas of optimal Iodine intake (India is included in this category since 2004) ${ }^{6,7}$, Hypothyroidism is more common than hyperthyroidism with a female-tomale ratio of $3: 1$, in population-based studies ${ }^{8,9,10}$. The findings of our study are in agreement with the earlier research, although the relative frequency of patients of hypothyroidism and those of hyperthyroidism cannot be compared as all the studies reviewed by us included patients suspected of having thyroid dysfunction or included only hypothyroid or hyperthyroid patients.

As per our study, $28.9 \%$ of hypothyroid patients had mild depressive symptoms while $29.4 \%$ of them had moderate depressive symptoms based on the scores obtained on the H.D.R.S. The corresponding figures for hyperthyroid patients were $56.2 \%$ and $6.3 \%$ respectively. There is a wide variation in the literature regarding the frequency of depression in hypothyroidism as well as hyperthyroidism. This can be attributed to the fact that different studies have based their findings on different screening instruments. The frequency of symptoms of depression has been reported to vary from 12.5 to $63 \%^{11,12,13,14,15}$. The findings of our study are in agreement with those of the earlier studies. The frequency of symptoms of depression in hyperthyroidism has been reported to vary from 30 to 70 percent across different studies which are in agreement with the findings of our study.

The results of our study show that $56.2 \%$ of hyperthyroid patients while $47.1 \%$ of hypothyroid patients had moderate to severe anxiety as indicated by the scores obtained on the H.A.R.S. Bathla et al in $2016^{11}$ reported some degree of anxiety in $63 \%$ patients of hypothyroidism using the same assessment tool. $23 \%$ patients had moderate to severe anxiety. Other studies using H.A.R.S. have reported the frequency of anxiety to range from 20 to 40 percent. ${ }^{16,17,18}$ The findings of our study show a higher frequency of anxiety symptoms in patients of hypothyroidism. This calls for a detailed and more broad-based study to be carried out in this part of India.

The frequency of hyperthyroid patients having significant anxiety was found out to be $53 \%$ in a study conducted by Shoib et al in 2013. The findings of our study are in agreement with those of the aforementioned study.

We also evaluated the frequency of depressive symptoms in our study sample with the help of Amritsar Depressive Inventory (A.D.I.) which is a patient-rated scale. We found clinically significant depression in $47.1 \%$ of hypothyroid patients while the corresponding figure for hyperthyroid patients was $31.3 \%$. We were unable to find any previous study which evaluated depressive symptoms in patients of thyroid dysfunction based on a patientrated scale. 
We found $47.1 \%$ of hypothyroid patients had an Axis I Psychiatric diagnoses (as per ICD-10 criteria) while the corresponding figure was $62.5 \%$ for hyperthyroid patients. The commonest Axis I diagnoses among hypothyroid patients was Depression (44.1\%) while it was Panic disorder in hyperthyroid patients $(31.3 \%)$. Aslan et al ${ }^{19}$ found that $43 \%$ of hyperthyroid patients had an Axis I diagnosis. Hall in 1983 and Haug et al ${ }^{17}$ in 2004 reported an Axis I diagnosis of Anxiety disorder in 30-40\% patients of hypothyroidism. The prevalence of Major Depressive Disorder was reported to be $24.2 \%$ while that of an Anxiety disorder was reported to be $23 \%$ by Shoib et $\mathrm{al}^{16}$. The figure for prevalence of depression in patients of hyperthyroidism is higher than those reported in earlier researches.

\section{Clinical Implications}

The findings of our study underscore the need of a liaison with a psychiatrist in every patient of thyroid dysfunction. This would greatly help improve the quality of life of these patients and would lead to better outcomes both in the short and longterm.

\section{References}

1. D'haenen $\mathrm{H}$, Boer JAD, Wilner $\mathrm{P}$. Biological Psychiatry. Vol. 1. Chichester, UK: Wiley; 2002.

2. Vandoolaeghe E, Maes M, Vandevyvere J, Neels H. Hypothalamic-pituitary-thyroid axis function in treatment-resistant depression. Journal of Affective Disorders. 1997; 43(2): 143-150.

3. Hamilton M. A rating scale for depression. J Neurol Neurosurg Psychiatry. 1960;23:56-62.

4. Hamilton M. The assessment of anxiety states by rating. $\mathrm{Br} \mathrm{J}$ Med Psychol. 1959;32:50-5.

5. Gurmeet Singh, Verma, H.C., Verma, R.S., and Kaur, H. 1974. A New Depressive Inventory-Amritsar Depressive Inventory. Indian J. Psychiat. 16: 183-88.
6. Andersson M, Takkouche B, Egli I, Allen HE, Benoist B. (2005) Currentglobal iodine status and progress over the last decade towards the elimination of iodine deficiency. Bull World Health Organ.83:518-525.

7. Iodine status worldwide, WHO global database on iodine deficiency, Department of nutrition for health and development. Geneva: WHO; (2004).

8. Unnikrishnan AG, Kalra S, Sahay RK, Bantwal G, John M, Tewari N. (2013). Prevalence of hypothyroidism in adults: An epidemiological study in eight cities of India. Indian $\mathrm{J}$ Endocrinol and Metab. 17(5):647-652.

9. Jatwa J and Ismail B. (2012) Studies on Human Thyroid disorders based upon Assay of TSH and Thyroid hormones in Ujjain, MP, India. ISCA Journal of Biological Sciences. 1(2):43-47.

10. Bose A, Sharma N, Hemvani N, Chitnis DS. A Hospital Based Prevalence Study on Thyroid Disorders in Malwa region of Central India. Int.J. Curr. Microbiol. App.Sci (2015) 4(6): 604-611.

11. Bathla M, Singh M, and Relan P. Prevalence of anxiety and depressive symptoms among patients with hypothyroidism. Indian $\mathrm{J}$ Endocrinol Metab. 2016 Jul-Aug; 20(4): 468-474.

12. Pies RW. Women, mood, and the thyroid. Women Psychiatry Health. 1995 ;4:4-10.

13. Chaudhary R, Chabra S, Singla M, Mishra BP, Sharma A. Psychiatric morbidity among hypothyroid patients - A hospital based study. Delhi Psychiatry J. 2014;17:35-8.

14. Saltevo J, Kautiainen H, Mäntyselkä $P$, Jula A, Keinänen-Kiukaanniemi S, KorpiHyövälti E, et al. The relationship between thyroid function and depressive symptoms-the FIN-D2D population-based 
study. Clin Med Insights Endocrinol

Diabetes. 2015;8:29-33.

15. Gupta S, Saha PK, Mukhopadhyay A. Prevalence of hypothyroidism and importance of cholesterol estimation in patients suffering from major depressive disorder. J Indian Med Assoc. 2008; 106:240-2.

16. Shoib S, Mushtaq, Dar MM, Arif T. Psychiatric Manifestations in thyroid disorders. International Journal of Clinical Cases and Investigations 2013. Volume 5 (Issue 3),84:98.

17. Haug TT, Mykletun A, Dahl AA. The association between anxiety, depression, and somatic symptoms in a large population: The Hunt-II study. Psychosom Med. 2004;66:845-51.

18. Hall RC. Psychiatric effects of thyroid hormone disturbance. Psychosomatics. 1983;24:7-22.

19. Aslan S, Ersoy R, Kuruoglu AC, Karakoc A, Cakir N. Psychiatric symptoms and diagnoses in thyroid disorders: a crosssectional study. Int $\mathbf{J}$ Psychiatry Clin Pract. 2005;9(3):187-92. 